\title{
Travel patterns and challenges experienced by University of Johannesburg off-campus students
}

\author{
Authors: \\ Tatenda C. Mbara ${ }^{1}$ \\ Cynthia Celliers ${ }^{1}$ \\ Affiliations: \\ ${ }^{1}$ Department of Transport \\ and Supply Chain \\ Management, University of \\ Johannesburg, South Africa \\ Correspondence to: \\ Tatenda Mbara \\ Email: \\ tmbara@uj.ac.za \\ Postal address: \\ PO Box 524, Auckland Park \\ 2006, South Africa \\ Dates: \\ Received: 05 Aug. 2013 \\ Accepted: 25 Oct. 2013 \\ Published: 28 Nov. 2013 \\ How to site this article: \\ Mbara, T.C., Celliers, C., \\ 2013, 'Travel patterns and \\ challenges experienced by \\ University of Johannesburg \\ off-campus students', Journal \\ of Transport and Supply \\ Chain Management 7(1), Art \\ \#114, 8 pages. http://dx.doi. \\ org/10.4102/jtscm.v7i1.114

\section{Copyright:} \\ (C) 2013. The Authors. \\ Licensee: AOSIS \\ OpenJournals. This work \\ is licensed under the \\ Creative Commons \\ Attribution License.
}

Read online:

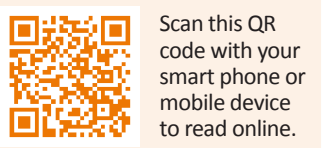

When universities across the world emerged, the majority of students were provided with oncampus accommodation. However, with the increase in the number of universities, students seeking to enter universities and the decline in university funding, the result was an increase in the number of students residing off-campus. This lead to more limited social-contact opportunities with other students, which are vital for the enhancement of their learning and development. It also resulted in off-campus students spending a considerable amount of time travelling to and from university. This study aimed to investigate the travel patterns, characteristics and challenges faced by University of Johannesburg off-campus students by ascertaining inter alia: the means of transport used; travel time; the views of students in regard to the challenges they face; and possible improvements thereto. A quantitative approach was predominantly used to collect data from students by means of a questionnaire and this was supplemented with focus group discussions on two campuses. The study results revealed that off-campus students experience considerable challenges accessing campuses.

\section{Introduction}

When universities across the world emerged, the majority of students were provided with oncampus accommodation. However, with the increase in the number of universities, students seeking to enter universities and the decline in university funding, the result is an increase in the number of students residing off-campus.

As the university student population has increased, there has been a concomitant decrease in higher education funding, which in turn has affected investment in university infrastructure; including student accommodation. The two main sources from which universities can obtain funds are Government and student fees. These two sources cannot provide adequate funds to sustain academic institutions. Consequently, universities are compelled to look for other ways of generating income. The other avenues that have been considered include investments, donations and entrepreneurial activities. However, the proportion of income that has been sought through these avenues for all the 23 universities in South Africa decreased from 33\% in 2008 to 31\% in 2010 (Higher Education in Context 2011).

Against this backdrop, it is important to note that the number of students staying off-campus generally exceeds those who reside on-campus. Furthermore, off-campus students are disadvantaged when compared to their on-campus counterparts as they spend a lot of time travelling to and from University; time which could otherwise be used productively in studying and building important social relationships and networks.

When conducting the literature search for this study, it became evident that there is little research that has been undertaken on the transport challenges experienced by off-campus students. Most universities are more concerned with the provision of transport for students who reside in university-managed accommodation and inter-campus linkages. For example, the University of Cape Town operates a bus service known as the 'Jammie Shuttle', which connects universitymanaged residences to all UCT campuses. The University of The Witwatersrand also provides bus transport from campuses to university-managed residences. The University of Johannesburg runs an inter-campus bus service that connects its four campuses. Thus, the challenges experienced by the majority of students who travel from privately rented accommodation or their homes constitute a less-researched area.

Section 29 of the Republic of South Africa constitution stipulates that 'Everyone has the right to a basic education' (Government of South Africa 1996:14). Clearly, the right to basic education entails easier access. The Learners Oxford Dictionary defines accessibility as 'the ease with which one reaches a desired location'. A simple deduction from this definition is that accessibility can be 
achieved by greater proximity and improved mobility, thus, transport is an important component of accessibility.

In South Africa, much of the research undertaken on learner transport (Rogan 2006; Behrens 2004) has invariably focused on primary and secondary school students.

This study aimed to investigate the travel characteristics, patterns and challenges faced by off-campus students at the University of Johannesburg. Since the University of Johannesburg has four campuses, the study also sought to establish whether the travel patterns are different among the campuses. The specific objectives were to:

- Ascertain the modes of transport used by students when accessing the university.

- Determine the travel time spent when travelling to the university.

- Find out the views of students in regard to the travelling problems they face, if any, as well as their perceptions on how travelling can be improved.

- Make the necessary recommendations that may alleviate the travelling challenges faced by students.

\section{Literature review}

There has been a significant worldwide growth of tertiary institutions within the last two decades. The growth has not only been confined to an increase in the number of tertiary institutions, but an expansion of existing ones as well. In most of the world's wealthier nations, the proportion of the population undertaking higher education has grown by $20.0 \%$ in the present century. In many developing countries and emerging economies the growth has been even faster (Williams 2011). For instance, China and India have both experienced unprecedented growths in their Higher Education sectors in the last decade. Student enrolment in Higher Education institutions in China increased from two million students in 1997 to the current 27 million, making the Higher Education sector the highest in the world ( $\mathrm{Wu} \&$ Zheng 2008). India, with more than 400 universities, has experienced an annual growth rate of approximately 6.0\% since 1985 (University World News 2009). In South Africa, according to Higher Education in Context (2011), the population of university students in the country increased from about 473 000 in 1993 to approximately 799700 in 2008. This shows that within a period of 16 years the student population almost doubled; this increase equates to $4.3 \%$ growth per annum. Rensburg (2011) highlighted the serious shortage in student accommodation at South African universities, as evidenced by the total number of beds at all universities, which stood at 107598 in 2010, equating to $20.0 \%$ of the total enrolment.

The unprecedented growth in the number of university students has clearly created accommodation constraints, forcing many students to stay off-campus. According to Horn and Berktold (2002), approximately $86 \%$ of college and university students in the United States of America (USA) are defined as commuter students, that is, students living off-campus. In 2010, the University of Johannesburg had only 6000 students accommodated on-campus from a student population of approximately 48000 (University of Johannesburg 2010). Thus, approximately $78 \%$ of students are compelled to seek off-campus accommodation and travel to the university for lectures.

Tinto (1987) concluded that students who reside off-campus are disadvantaged when compared to their on-campus counterparts. He found that the former group spent less time on campus creating relationships with other students and staff and clearly had fewer opportunities to engage in quality interactions. Thus, these students are less likely to make a strong commitment to their studies. Rensburg (2011) made a pertinent observation and stated that because of:

the high levels of poverty in Africa and the unsuitability of the home environment for academic endeavo[u]r for the majority of students, suitable student accommodation needs to be provided for up to $100 \%$ of students in some contexts.

Apart from limited social contact opportunities with other students, which are vital for the enhancement of their learning and development, they also spend a considerable amount of time travelling to and from the university. This is unproductive time and does not add any value to their learning.

Some university academic programmes may be scheduled during weekends, early mornings or late evenings. Such times are inconvenient to off-campus students and staff who may have to adjust their travelling schedules. Thus, these students are likely to encounter problems in adjusting schedules and attending classes at such times. Evening classes also pose a security risk to students.

There are also numerous external factors, such as congestion and unreliable public transport systems, which may result in some students arriving late, tired or missing lectures altogether with adverse effects on their learning. A study by Kasayira et al. (2007) found that out of the 11 stressors that faced students at one university, transport ranked fifth.

\section{Research method and design}

For this study, a quantitative approach was predominantly used to collect data from students by means of a questionnaire. All the four University of Johannesburg (UJ) campuses were covered. Quantitative data was supplemented with focus group discussions (FGD), which were conducted on two campuses, namely: Auckland Park Bunting (APB) and Soweto Campus (SWC). Auckland Park Bunting (APB) campus was chosen for convenience sake, as the authors are based on this campus. Soweto campus (SWC) was chosen as it is located far from the other three campuses and the CBD.

The questionnaire was administered to only second-year students. Clearly, it would be difficult to come up with a sample that covers all the groups at undergraduate and postgraduate levels; hence the decision to focus on one yeargroup level. The first-year students are new to the university, so they may take time to settle and there is a likelihood 
of them changing accommodation from time to time. A relatively high proportion of third-year students are likely to have secured jobs and thus their travelling patterns may be different.

In respect to the actual data collection from students, questionnaires were given to lecturers of sampled classes for distribution in class. The questionnaires were retrieved at the end of the lecture.

In 2012, the University of Johannesburg registered a total of 48864 students, comprising 6528 postgraduates and 42336 undergraduates. The second year was comprised of 12576 students, equating to $29 \%$ of the undergraduates. Taking into cognisance the proportion of students on each campus, an appropriate sample was drawn from the second years. Table 1 shows the number of second-year students on each campus.

In drawing up the sample, a $4 \%$ maximum error at $95 \%$ confidence level was allowed. The sample from each campus was drawn as follows:

$n=\left(\pi[1-\pi][1.96]^{2}\right) \div(0.04)^{2}$

[Eqn 1]

Where:

$n=$ Number of questionnaires

$\pi=$ Proportion of second year students

For instance, the sample for APB was calculated as follows:

$n=\left(0.18[1-018] \times[1.96]^{2}\right) \div(0.04)^{2}$

$=354$ questionnaires (minimum)

[Eqn 2]

On the basis of the above computation, the minimum number of questionnaires from other campuses was: 600 for Auckland Park Kingsway (APK), 355 for Auckland Park Bunting (APB), 307 for Doornfontein (DFC) and 339 for Soweto campus; making a total of 1601 questionnaires. However, the total number of students interviewed came to 1707, comprising 626 APK, 381 APB, 334 DFC and 366 SWC, which was marginally more than the minimum sample required.

A study of this nature calls for a clear way in which the ethical issues are addressed. Therefore, the following were undertaken:

- The permission of the relevant institutional Department(s) or Committee(s) of UJ was sought.

- A letter explaining the purpose of the survey was attached to questionnaires requesting the participation of the

TABLE 1: The number of second year students registered at the University of Johannesburg in 2012.

\begin{tabular}{lll}
\hline Campus & Second Years & $\mathbf{\%}$ \\
\hline APB & 2318 & 18.4 \\
APK & 6081 & 48.4 \\
DFC & 2003 & 15.9 \\
SWC & 2174 & 17.3 \\
\hline Total & $\mathbf{1 2 5 7 6}$ & $\mathbf{1 0 0 . 0}$ \\
\hline
\end{tabular}

Source: based on HEDA information

APB, Auckland Park Bunting Road Campus; APK, Auckland Park Kingsway Campus; DFC Doornfontein Campus; SWC, Soweto Campus. respondent. In addition, an undertaking was given that the data would be used collectively, solely for research purposes and no names would be required.

- The researchers undertook to analyse and interpret the findings of the study objectively and not allow their personal views to influence the results.

- Any respondents who declined to participate in the survey were removed from the study and their reasons for not participating were respected.

- Organisations that assisted in the survey were given a copy of the results on request.

\section{Setting}

University of Johannesburg is comprised of four campuses, namely: Auckland Park Kingsway (APK), Auckland Park Bunting (APB), Doornfontein (DFC) and Soweto (SWC). The University is a result of a merger between the then Rand Afrikaans University (RAU) and Technikon Witwatersrand. All four campuses are within the metropolitan area of the City of Johannesburg. Doornfontein is located within the Central Business District (CBD). Auckland Park Kingsway and APB, which are $2 \mathrm{~km}$ apart, are both located in Auckland Park, approximately $6 \mathrm{~km}$ from the CBD. Soweto is located on the outskirts of the Soweto residential area and approximately $22 \mathrm{~km}$ from the Johannesburg CBD.

\section{Results}

\section{Characteristics of interviewees}

Out of the 1707 students interviewed, 952 were female and 755 were male, equating to $56 \%$ and $44 \%$ respectively. Fifty four percent $(54 \%)$ were pursuing a National Diploma or Diploma, whilst $46 \%$ were enrolled for a Degree. The majority of students (92\%) were full time, with $8 \%$ studying on a parttime basis. Ninety six percent $(96 \%)$ of students interviewed were in the 18-25 year age group, which was consistent with expectations, as the study was confined to second-year undergraduates.

\section{Origin of students}

The data of where the students studying at the four campuses originated from showed six broad origins. Notwithstanding the numerous origins, for simplicities sake, data were collapsed into six areas to show students' origins. The majority of students originated from areas close to the campus on which they were studying. For instance, approximately $60 \%$ of students studying at the DFC resided in the neighboring residential areas surrounding the campus. At SWC, 57\% of students originated from the Soweto residential area. For APB and APK, the local residences constituted $33 \%$ and $39 \%$ respectively. This suggested that most off-campus students tried to secure accommodation near to the campus at which they studied, ostensibly to save on both time and transport costs. Figure 1, Figure 2, Figure 3 and Figure 4 succinctly portray the origins of students and it is evident that the majority of these students resided close to the campus at which they were studying. 


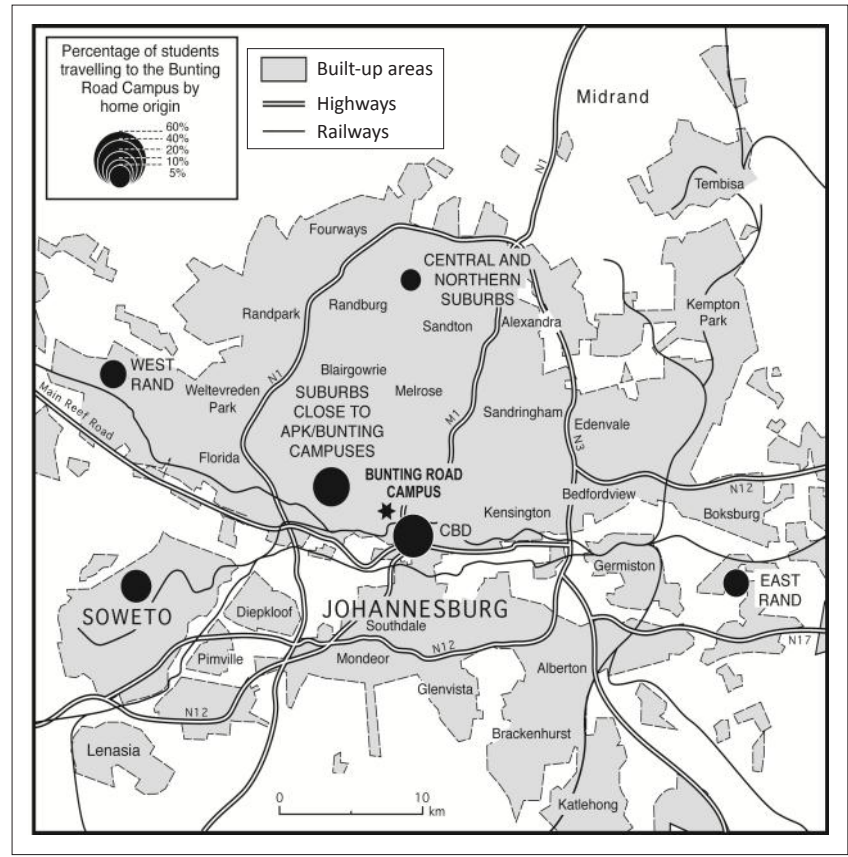

FIGURE 1: Origin of Auckland Park Bunting Road Campus students.

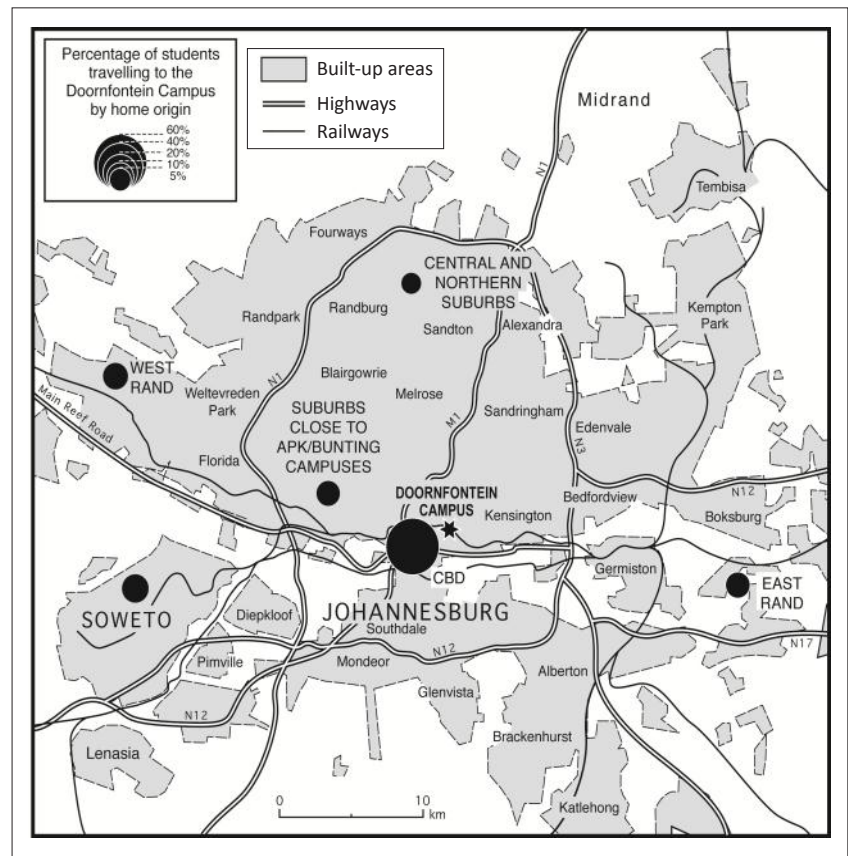

FIGURE 2: Origin of Doornfontein Campus students.

\section{Means of transport used}

For all the four campuses combined, students made an average of five trips per week using a variety of transport modes. Walking (33\%) was the most common means of transport used by students at all the four campuses. This was followed by bus (25\%), minibus (21\%) and car (14\%). Rail, metered taxi, bicycle and motorbike use was small. When the data were computed for each campus, there were variations in the use of the different modes of transport, as depicted by Figure 5 . For instance, of the total number of students interviewed at DFC, 57\% walked. The corresponding figures of students that walked at the other campuses were: APB $25 \%$, APK $32 \%$ and SWC 20\%.

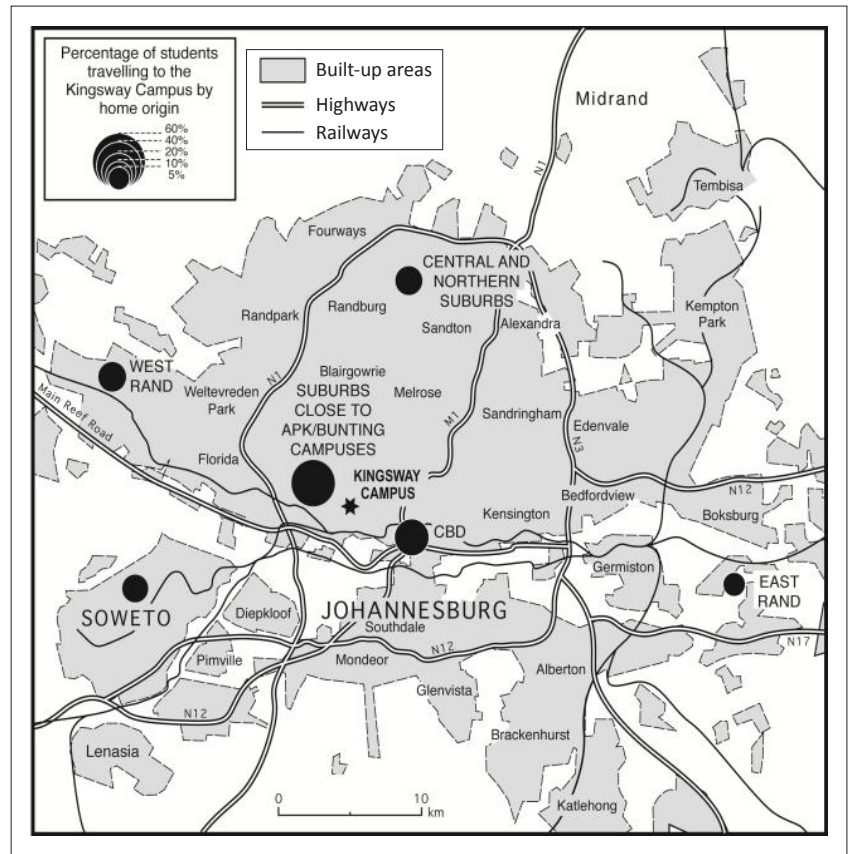

FIGURE 3: Origin of Auckland Park Kingsway Campus students.

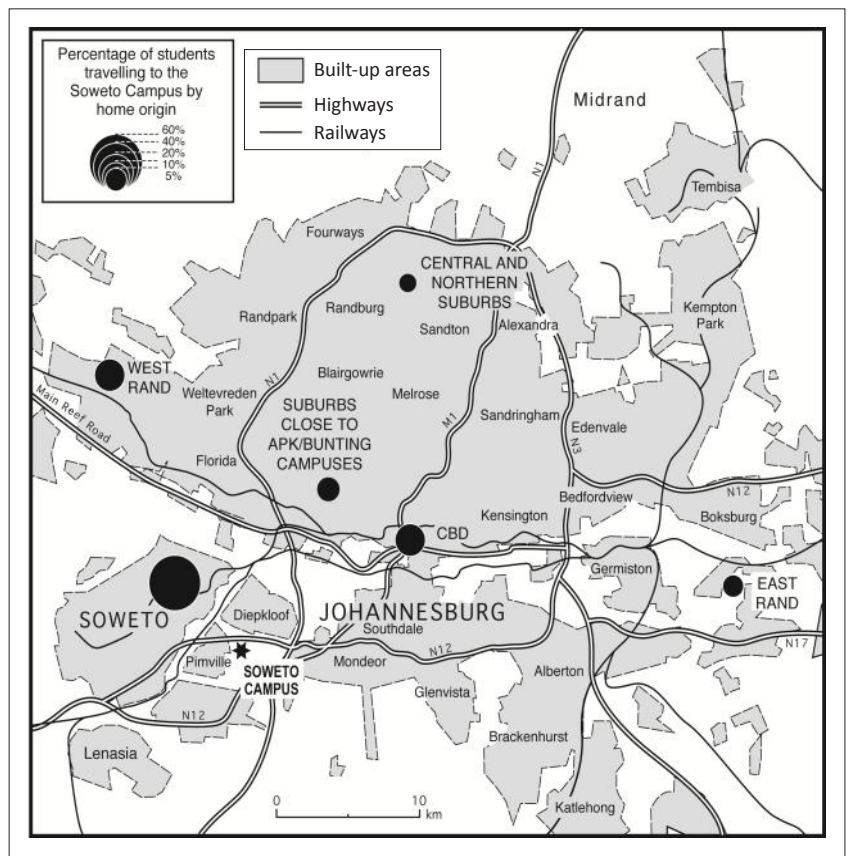

FIGURE 4: Origin of Soweto Campusstudents.

A significant proportion of SWC-based students (37\%) used minibuses, compared to $21 \%$ at $\mathrm{APB}, 16 \%$ at APK and $12 \%$ at DFC. The campuses' share of conventional buses was as follows: $36 \%$ at APB, $24 \%$ at APK, $14 \%$ at DFC and $20 \%$ at SWC. Interestingly, there was a marked difference in bus use between APK and APB, notwithstanding the closer proximity of the two campuses. In respect of car use, APK had the highest percentage of $22 \%$, whilst each of the other three campuses had a figure of less than $10 \%$.

In light of the above variations, it became necessary to carry out a test of significance (Chi-squared tests) in order to ascertain the statistical differences in use of transport modes at the four campuses. The test revealed: 
Null Hypothesis (Ho): there is no association between campuses and type of transport.

Alternative Hypothesis: there is an association between campuses and type of transport.

$$
\begin{aligned}
& x^{2}=422.538, \\
& (d f=21), \\
& p=0.000
\end{aligned}
$$

As $p<0.005$, the Null hypothesis is rejected.

Interestingly, the statistical analysis and results showed that there was an association between campus and type of transport. It was expected that for a university, there would be no relationship between type of transport and campus. However, the location of the campus appeared to be a major factor that influenced the type of transport used to access the campus. For instance, DFC is located on the edge of the Johannesburg CBD. The high percentage of students that walked suggests that a lot of students were renting affordable accommodation within the $\mathrm{CBD}$ and the contiguous residential areas like Berea, Yeovil and Kensington.

The dominant use of minibuses by students at SWC could easily be explained by the location of the campus, which is on the outskirts of Soweto. The majority of SWC-based students resided in Soweto and the minibus was the predominant mode of transport in this residential area. Minibus routes from within the residential area to Johannesburg CBD passed through SWC.

The use of a car by APK students was conspicuous in comparison with other campuses. The location factor could not provide a plausible explanation, as APB (where students predominantly used buses) and APK are located in the same residential area and only $2 \mathrm{~km}$ apart. This suggested differences in the type of students on the two campuses. At APK, students were mainly pursuing degree programmes, whereas at APB the majority was studying National Diploma courses. The higher use of a car at the APK campus may reflect the past historical legacies. APK has retained its status as an academic-orientated campus offering mainly degree and postgraduate programmes; it attracts students from more affluent families. The other campuses (which were formerly Technicons) tend to offer mainly vocational-orientated programmes.

\section{Travel time and waiting time}

Travel time and waiting time are important measures of service quality. Excessively long travel and waiting times constitute unproductive time, which cannot be utilised and therefore does not add any value to students' learning.

Students took an average of $38 \mathrm{~min}$ to travel to campus. The average travelling times for the different campuses were: 43 min for APB, 35 min for APK, 30 min for DFC and 45 min for SWC. Notwithstanding these relatively moderate averagetravelling times, there were students residing outside Gauteng (albeit in the minority and not attending lectures daily) whose travelling time was in excess of five hours.
Students who used public transport experienced longer waiting times. As already alluded to, time spent waiting for public transport is a cost, as it cannot be profitably used. Average waiting times of taxi, bus and rail were $15 \mathrm{~min}, 24$ min and 26 min respectively. Notwithstanding the limited capacity of a taxi compared to a conventional bus and rail, the taxi had the lowest average waiting time. This clearly showed the high frequency offered by taxis. Figure 6 illustrates the cumulative waiting time by each mode.

Figure 6 clearly shows that taxis have lower waiting times than the other modes. For instance, approximately $90 \%$ of students using a taxi waited for less than $30 \mathrm{~min}$, whilst the same proportion of students using bus and rail waited for less than $50 \mathrm{~min}$ and $60 \mathrm{~min}$ respectively.

\section{Number of modes used}

Figure 7 illustrates the number of modes used by students when accessing the campus at which they studied.

Approximately $77.0 \%$ of students used only one mode of transport, thus making a direct journey to the campus at which they were studying without needing to change. Of the $77.0 \%$ of students who used one mode of transport, the

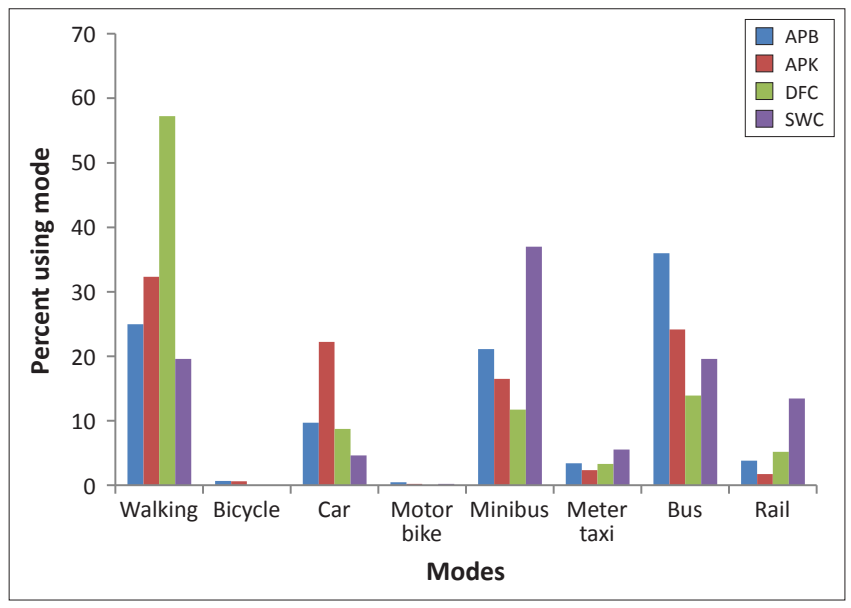

APB, Auckland Park Bunting Road Campus; APK, Auckland Park Kingsway Campus; DFC, Doornfontein Campus; SWC, Soweto Campus.

FIGURE 5: Means of transport used to access campuses.

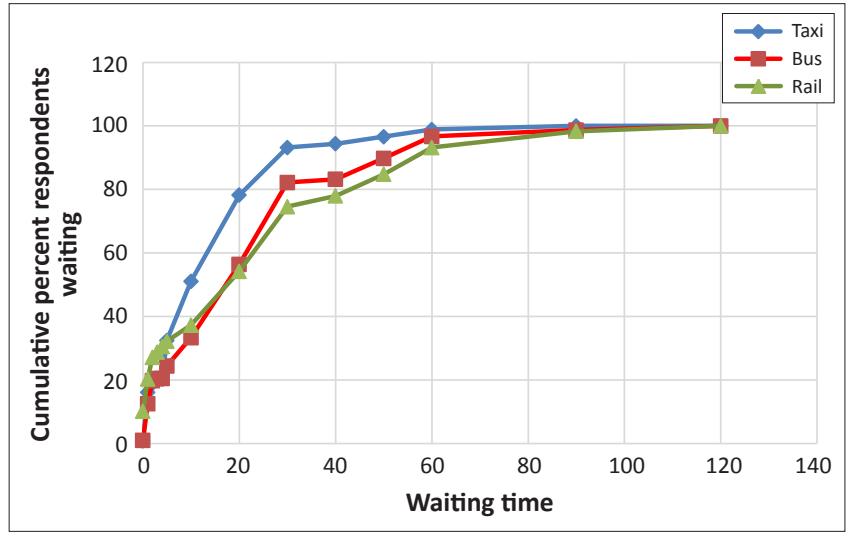

APB, Auckland Park Bunting Road Campus; APK, Auckland Park Kingsway Campus; DFC, Doornfontein Campus; SWC, Soweto Campus.

FIGURE 6: Cumulative waiting time by mode. 
breakdown per campus was as follows: $80.0 \%$ for APK, $67.0 \%$ for APB, $78.0 \%$ for DFC and $77.0 \%$ for SWC. Eighteen percent $(18.0 \%)$ of students made use of two modes of transport, $4.5 \%$ used three modes and less than $1.0 \%$ used more than four modes to reach the campus of study. From the $18.0 \%$ of students who used two modes of transport to access the campus of study, the breakdown per campus was as follows: $16.0 \%$ for $\mathrm{APK}, 23.0 \%$ for $\mathrm{APB}, 18.0 \%$ for $\mathrm{DFC}$ and $18.0 \%$ for SWC. The number of students who used more than four modes was very small.

The key difference appears to be APB, whose proportion of students making a direct trip to the campus was considerably lower than the other three. A question could be raised as to why APK and APB had different proportions of students making a direct trip, considering the fact that the two campuses are located in the same neighbourhood. The higher number of direct trips for APK appeared to be boosted by a higher percentage of students using a private car. This also suggested that the higher percentage of students who used public transport for APB made an interchange in the CBD. Due to the location of DFC, which is in the CBD, some students walked to the campus from the various public transport termini; hence a higher proportion of students who used a single mode in comparison with APB.

The differences were tested statistically as follows:

Null Hypothesis (Ho): there is no association between campuses and number of modes used.

Alternative Hypothesis: there is an association between campuses and number of transport.

$$
\begin{aligned}
& \mathrm{x}^{2}=41.65, \\
& (d f=15), \\
& p=0.000
\end{aligned}
$$

As $p<0.005$, the Null hypothesis is rejected.

From the above results, there appears to be an association between campus and number of transport modes used. This is more a reflection of the location of the campus and the means of transport used. A campus like APK, with a higher proportion of students using private cars, is bound to have a larger proportion or higher percentage using one mode of transport to access the campus. A campus like DFC, which is located in the CBD where public transport converges, is likely to have a higher percentage of students using a single mode to access the campus than APB, which is on the outskirts of the CBD.

Whilst the number of students who used more than three modes of transport to access the campus of study was small $(6 \%)$, the challenges associated with such travel were quite considerable. During the focus group discussions, students were accorded an opportunity to map the travel pattern from their respective places of residence to the campus at which they were studying. Figure 8 illustrates the travel pattern of a Soweto-based student who stayed in Brakpan (East Rand).

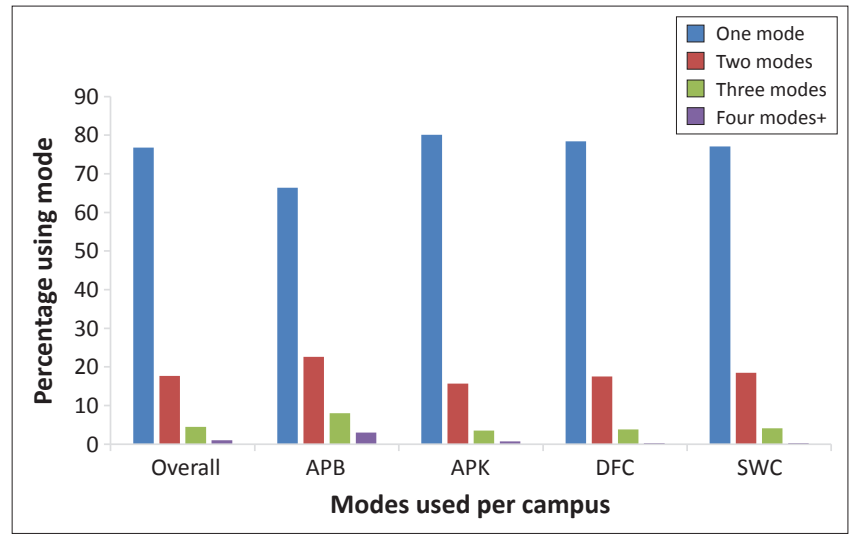

APB, Auckland Park Bunting Road Campus; APK, Auckland Park Kingsway Campus; DFC, Doornfontein Campus; SWC, Soweto Campus.

FIGURE 7: Number of modes used by students to access the campus of study.

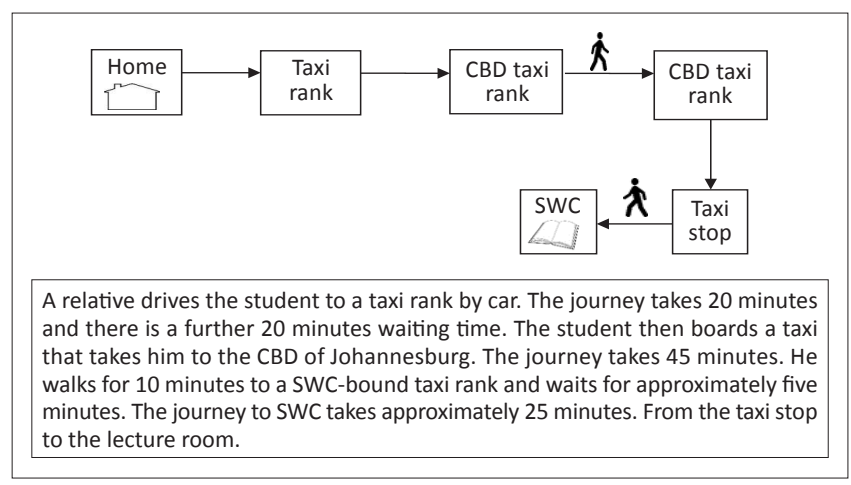

CBD, Central Business District; SWC, Soweto Campus.

FIGURE 8: Travel pattern of a Soweto based student.

The student used five modes of transport (including walking) and took approximately $125 \mathrm{~min}$ to reach the campus. The student admitted that he was always late for lectures. The same student lamented the public transport network and emotionally asked, 'Why should all public transport services be focused on the Johannesburg Central Business District?' Apart from arriving late, the student reported that he was always tired, which negatively affected his concentration.

\section{Travel cost}

Due to inconsistences in interpreting the questionnaire with respect of travel cost, it was not possible to compute the travel costs incurred by students. Some students indicated a one-way travel cost, whilst others gave a return-trip cost. However, transport cost was an issue and was vehemently spoken about by students during focus group discussions that rent off-campus accommodation. At APB, daily travel costs for the students that participated in the focus group discussion ranged from $\mathrm{R} 22$ to R88, with an average of R42. At SWC, it ranged from R15 to R60, with an average of R30. The proximity of SWC to the Soweto residential area contributed to lower average travelling costs compared to APB. The weekly average travel costs translated to R210 and R150 for APB and SWC respectively. Whilst students who stayed with close relatives did not incur any rental costs, they perceived the transport cost as a tradeoff to the accommodation fees that they would pay if they were staying in on-campus residence. 


\section{Travel challenges and solutions}

Students were asked about the advantages and disadvantages of staying in on-campus university accommodation. The main advantages cited were: easy access to learning facilities, ability to grow and know how to budget, and security. Two main disadvantages were mentioned, namely: the inconvenience of vacating on-campus accommodation during vacation and 'countless' (as one mentioned) rules and regulations associated with campus accommodation.

Students experienced numerous challenges in accessing the campus of study. Apart from citing the problems that they faced when travelling to campus, they were also able to prescribe what they thought would be the solutions to these challenges. Table 2 summarises the major problems and solutions cited by the students.

It was evident from the questionnaire responses and the focus group discussions that the travel challenges experienced by students were considerable. The students who were not staying with parents or close relatives invariably would have preferred to stay on-campus if accommodation was available.

Traffic congestion, long waiting times for public transport, harassment from taxis and muggings are well known problems that are frequently highlighted in both the print and electronic media. Malfunctioning traffic lights are also an issue that affects the smooth flow of traffic, thus causing delays.

The proposed solution to have buses starting in all residential areas where students reside may be impractical. However, this does emphasise the need to revisit the public transport network in the City of Johannesburg. The planning of public transport is very much focused on the CBD and formal intersuburban public transport hardly exists.

Provision of infrastructure for non-motorised transport such as cycling is an interesting and plausible solution that needs to be seriously considered. At present, there is suppressed demand for bicycling in the city due to non-availability of the requisite cycling facilities. As much as some people (including

TABLE 2: Challenges experienced by students and their solutions.

\begin{tabular}{|c|c|}
\hline Challenges & Solutions \\
\hline $\begin{array}{l}\text { No direct services between place of } \\
\text { residence and campus }\end{array}$ & $\begin{array}{l}\text { Direct buses from residential areas to } \\
\text { campus }\end{array}$ \\
\hline Traffic congestion & Student discounts on public transport \\
\hline Waiting in queues for long periods & $\begin{array}{l}\text { City of Johannesburg to provide } \\
\text { infrastructure for cyclists }\end{array}$ \\
\hline Arriving late for lectures, tests and exams & Dedicated bus lanes \\
\hline Harassment from taxi drivers & Increase on-campus accommodation \\
\hline Inefficient public transport & Reduced fares for students \\
\hline Crime and robbery by thugs & Increase number of buses \\
\hline $\begin{array}{l}\text { Safety and security problems, especially } \\
\text { for female students }\end{array}$ & $\begin{array}{l}\text { Provide public transport from campus } \\
\text { to train stations }\end{array}$ \\
\hline Erratic train and bus schedules & - \\
\hline Accidents, notably by taxis & - \\
\hline High public transport fares & - \\
\hline Overcrowded and uncomfortable taxis & - \\
\hline Malfunctioning traffic lights and road blocks & - \\
\hline
\end{tabular}

students) may want to cycle, the current environment is not conducive to cycling. Sharing the road with motorised traffic is considered to be very dangerous. As one student remarked 'anyone who attempts to cycle in Johannesburg would need to be mentally examined'.

\section{Conclusion}

The University of Johannesburg, akin to many other universities in the country and world, accommodates a very small proportion of the student population in oncampus residences. The majority of students seek offcampus accommodation close to the campus at which they study. There is therefore a dire need for more on-campus accommodation. The recommendation by Rensburg (2011) to increase the bed capacity at universities by $50 \%-80 \%$, albeit an ambitious undertaking is a move in the right direction.

Walking is the most common means of transport used by students of the four UJ campuses. Conventional bus, minibus (taxi) and rail also constitute a significant share of means of transport used by students. Students take an average of $38 \mathrm{~min}$ to reach the campus of study. Of the three modes of public transport, the minibus taxi offers the lowest average waiting time of $15 \mathrm{~min}$. Notwithstanding the problems of overcrowding and other negative traits, the minibus taxi appears to offer a reliable service to students in regard to reduced travel and waiting time.

Statistically, there are differences in the type of mode as well as the number of modes used to access the campus of study. The location of the campus appears to be a major factor that influences the type of transport used to access the campus.

Students experience innumerable challenges travelling to campuses and these include: congestion, resulting in late arrival and missing some lectures; harassment from taxis drivers; and muggings inter alia. Provision of direct public transport links from residential areas to campuses, as well as from campuses to railway stations, and provision of appropriate infrastructure for bicycles are some of the overriding potential solutions cited by students. Clearly, the last proposal is an important one that would not only alleviate transport challenges, but would also significantly contribute to a sustainable urban environment.

\section{The following recommendations can be made:}

- Concerted efforts are required to build more on-campus accommodation in order to reduce the proportion of offcampus students who experience innumerable challenges travelling to and from campuses.

- The University should regularly engage planning authorities and public transport providers and impress upon them the need to focus on major traffic generators such as educational institutions in their future public transport network proposals.

- In view of the security concerns raised by students, the university needs to ensure that the walking routes and paths within the vicinity of campuses are not only well secured, but also provide a congenial walking environment. 
- In view of the expressed need to cycle to campus by some students, there is need for the City planning officials to provide the necessary infrastructure that is conducive to safe cycling.

- There is also a need for academics to conduct research in areas pertaining to attitudes towards cycling and technical ergonomics of bicycles appropriate for the local environment.

\section{Acknowledgements}

The authors wish to thank the following for their assistance: Lyness Matizirofa (lecturer at the Department of Statistics, University of Johannesburg), for her advice in determining the sample sizes; Richard Devey (Head of Statkon, University of Johannesburg), for organising data capture, analysing the data and interpreting it for us and Wendy Job (Department of Geography and Environmental Science, University of Johannesburg), for the production of maps showing the origins of students. Lastly to all the students who completed the questionnaires and those who participated in the focus group discussions and the Department of Transport and Supply Chain Management for paying for data capture and the production of the maps.

\section{Competing interests}

The authors declare that they have no financial or personal relationship(s) that may have inappropriately influenced them in writing this article.

\section{Authors' contributions}

T.M. (University of Johannesburg) was the study leader and responsible for conducting the literature search and drafting the article. C.C. (University of Johannesburg) organised the surveys and conducted part of the literature search.

\section{References}

Behrens, R., 2004, 'Child and Learner Travel in Cape Town: Problems and Prospects', Urban Forum 15(3), 254-278. http://dx.doi.org/10.1007/s12132-004-0003-7

Higher Education in Context, 2011, South African Higher Education, Fact and Figures, International Education Association of South Africa (IEASA), viewed 23 August 2013 , from http://www.ieasa.studysa.org/resources/Study_SA/Facts_Figures_section.pdf

International Education Association of South Africa (IEASA), 2011, Leaps and bounds: Growing higher education in South Africa, viewed 28 August 2013, from http:// www.ieasa.studysa.org/resources/Study_SA

Horn, L.J. \& Berktold, J., 2002, Commuter Students - Commuter Students Challenges, Education Encyclopedia - State University.com, viewed 09 November 2013, from http://www.education.stateuniversity.com/pages/1875/Commuter-Students.html

Kasayira, J.M., Chipandambira, K.S. \& Hungwe, C., 2007, 'Study on Stressors faced by University Students and their Coping Strategies: A Case Study of Midlands State University Students in Zimbabwe', 37th ASEE/IEEE Frontiers in Education Conference, Milwaukee, USA, October 10-13, 2007.

Rensburg, I., 2011, Report on the Ministerial Committee for the Review of the Provision of Student Housing at South African Universities, Dept. of Higher Education and Traning, South Africa.

Rogan, M.J., 2006, Dilemmas in Learner Transport: An Impact Evaluation of a School Transport Intervention in the llembe District, Kwazulu Natal, Masters thesis, School of Development Studies, University of KwaZulu Natal.

Tinto, V., 1987, Leaving College, University of Chicago Press, Chicago.

University of Johannesburg, 2010, Policy on the accreditation of off-campus accommodation, viewed 16 August 2010, from http://www.uj.ac.za/EN/StudyatUJ/ StudentFinance/NationalFinancialAidScheme/Documents/nsfas $\% 200 f$ ff 20 Campus\%20Accommodation\%20Policy.pdf

Williams, G., 2011, 'Will Higher Education be the Next Bubble to Burst?', The Europa World of Learning, viewed 18 May 2012, from http://www.educationarena.com/ pdf/sample/sample-essay-williams.pdf 